\title{
Appendicular mucocele as cause of intestinal intussusception: diagnostic by computer tomography
}

\author{
C. L. Fernández-Rey, S. Costilla García and A. M. Álvarez Blanco \\ Servicio de Radiodiagnóstico. Hospital Universitario Central de Asturias. Oviedo, Spain
}

\section{INTRODUCTION}

Approximately 10-30\% of intussusceptions that occur in adults are primary, frequently self-limited and not surgical (1, 2). The detection and frequency of these spontaneous and transient intussusceptions have been increased during the last years because of the widespread application of new imaging techniques as multislice computer tomography (CT) (1). But, in the majority of the obstructive cases there is a tumor that favours the intussusception acting as the lead point. This results in a permanent intestinal obstruction which needs surgical management (1-3).

Permanent or secondary intussusceptions constitute uncommon causes of intestinal obstruction. Frequently, they are associated with non specific symptoms that may simulate malignant neoplasms (1). The possible causes of bowel intussusceptions include benign and malignant lesions, such as colonic polyps and carcinomas, lipomas, lymphomas, melanoma metastases, post-surgical adherences and Meckel's diverticulum (1-3).

The preoperative diagnosis depends on the imaging methods. Ultrasonography may detect the intussusception but, multislice CT is the most sensitive diagnostic modality and provides information about the possible underlying lesions $(1,3)$. Thus, CT allows differentiate primary, self-limited and transient intussusceptions from secondary permanent intussusceptions that require surgery (1-3).

Appendicular mucocele has an approximate incidence of 0,2-0,3\% in appendicectomy and constitutes an infrequent cause of intussusception $(2,4)$. The histological analysis of the appendicular mucocele may correspond to any of the following entities: mucous retention cyst, mucous hyperplasia, cystadenoma or cystadenocarcinoma (4).

We report the case of a 40-year-old woman with polycystic kidney as unique clinical antecedent, who presents abdominal pain, constipation and palpable mass on the right flank. With the suspicion of colonic neoplasm an abdominal CT is

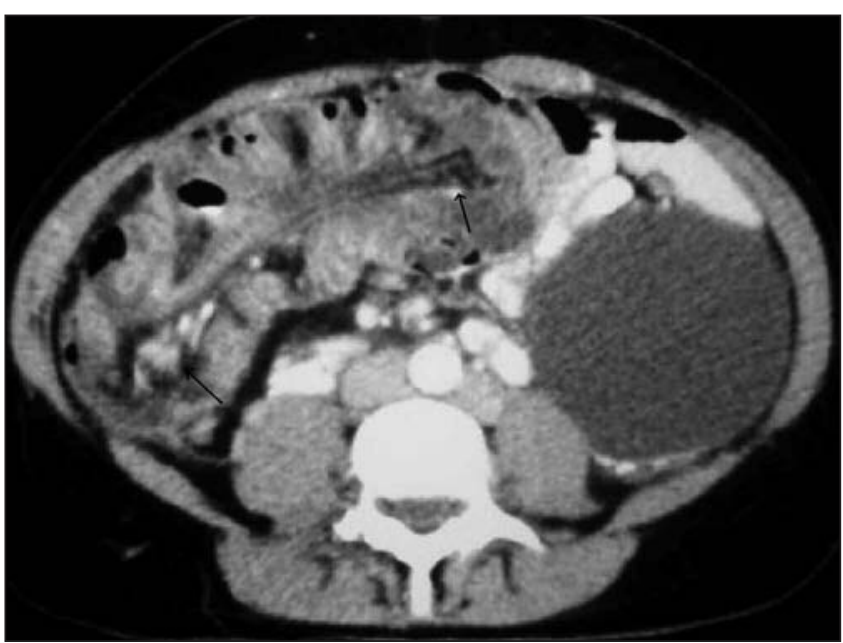

Fig. 1: Axial contrast enhanced CT image demonstrates an ileo-colic intussusception that originates a sausage-shaped cecum. Note the presence of fat and mesenteric vessels into the lumen of the right colon (black arrows).

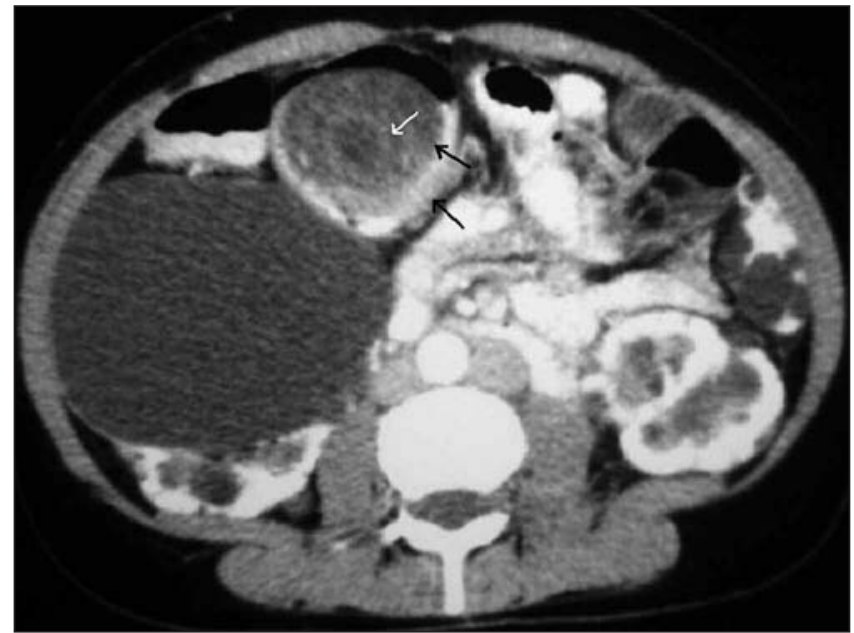

Fig. 2. Axial contrast enhanced CT image shows the bowel-within-bowel configuration with the classic "target sign" (black arrows). There is a lesion (white arrow) that acts as the lead point for intussusception. 


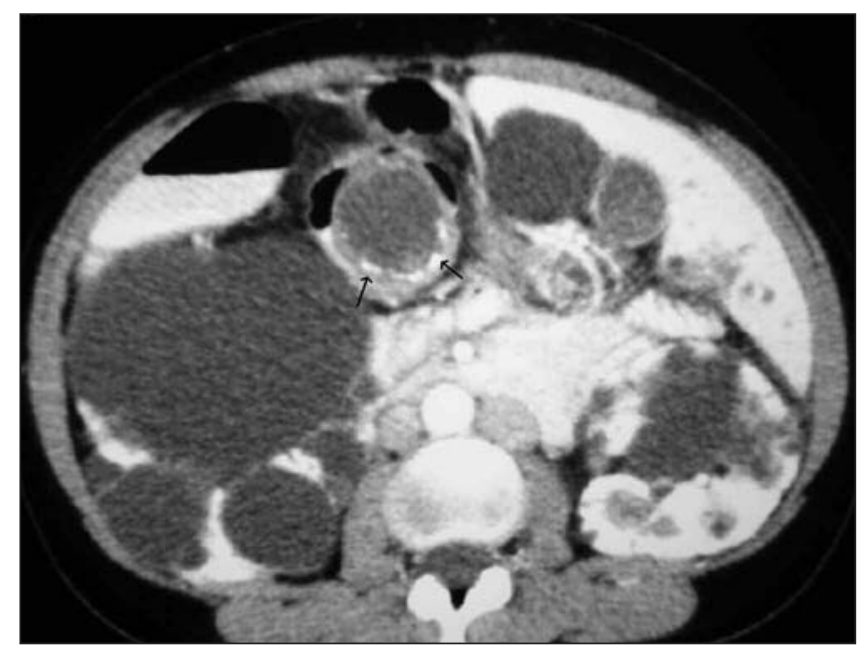

Fig. 3: Axial enhanced CT image demonstrates an appendicular mucocele with mural calcifications (black arrows) acting as the lead point for intussusception. performed, which demonstrates a thickened "sausage shaped" cecum (Fig. 1) and the pathognomonic bowelwithin-bowel configuration (Fig. 2), findings indicative of intussusception. An ovoid mass with fluid density, well-defined borders and mural calcifications located at the distal extremity of the intussusception is identified as the lead point for intussusception (Fig. 3). The final preoperative diagnosis is ileo-appendico-colic intussusception secondary to appendicular mucocele. The surgery confirms the CT findings and a segmental intestinal resection is performed. The histological analysis of the surgical specimen reveals an appendicular mucinous cystoadenoma.

\section{REFERENCES}

1. Kim YH, Blake MA, Harisinghani MG, et al. Adult Intestinal Intussusception: CT Appearances and Identification of a Causative Lead Point. RadioGraphics 2006; 26: 733-44.

2. Choi SH, Han JK, Kim SH, et al. Intussusception in Adults: From Stomach to Rectum AJR 2004; 183: 691-8.

3. Martín JG, Aguayo JL, Aguilar J, et al. Invaginación intestinal en el adulto. Presentación de siete casos con énfasis en el diagnóstico preoperatorio. Cirugía Española 2001; 70: 93-7

4. Bello Báez A, Cavada A, Alventosa E, et al. Mucocele apendicular, imagen por TC multicorte. Rev Esp Enferm Dig 2008; 100(9): 592-3. 